\title{
Technological Disintermediation: A Path to CSHP 2015 and Beyond
}

\author{
Richard Jones
}

$\mathrm{M}$

any of you will remember the long word "disintermediation” from presentations by former CSHP president Neil Johnson. Neil was referring to the development of personal data assistants (PDAs) as repositories of drug information that would displace pharmacists as "walking drug information encyclopedias". Neil's message was that pharmacists needed to truly understand their value in patient care or they would risk extinction, just as ice-box makers went out of business when electric refrigerators became available.

We are now experiencing an incredible expansion of technology in health care, with the development of tools such as PDAs containing drug libraries, electronic medical records, and robots for both compounding and dispensing, with many more yet to come. Despite the challenges of determining how to support these technologies financially, they represent the best opportunity for pharmacists to realize the vision that Roy Romanow suggested in his report a decade ago. ${ }^{1}$ They are also the key to realizing the vision articulated in CSHP 2015!

Imagine if you will, a production system in which dispensing technologies replace manual pick stations; compounding technologies replace the process of filling syringes by hand, the use of laminar airflow hoods, and even biohazard safety cabinets; PDAs and hospital computer networks make the full library of medical science, including compilations and analyses, available in any patient care setting; and similar technologies make the patient's complete care record and medication-related teaching tools for both health care providers and patients accessible wherever needed. In this production system of the future, what remains for pharmacists and pharmacy technicians to do?

Pharmacists will no longer have any direct connection to the distribution system, and will no longer be the ones to search for drugs that the nurses cannot find. Pharmacy technicians will be fully accountable for the operational system of the pharmacy, applying their talents to support the technology and any custom activities not amenable to technological solutions. They may even work on nursing units to directly address production and dosepreparation issues related to medications. Pharmacists will no longer be required to enter orders at a location distant from patients, and they will have limited need to spend hours in the library researching a particular

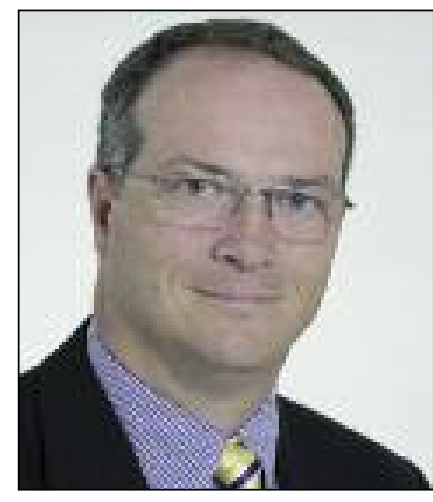
case so that they can assist in designing the best possible medication regimen for the patient. All the knowledge and information that pharmacists need will be at their disposal, and, conversely, the distribution system will function without input from pharamcists. Pharmacists will be truly free to work on the nursing units and to take full advantage of the opportunities associated with pharmaceutical care, achieving both the objectives of CSHP 2015 and the rewarding careers that they envisioned when they first graduated as pharmacists.

The ultimate outcomes of such a bold step would be significant and measurable improvements in quality of care and the safety of medication use. There is no better reason to grasp the opportunity offered by these technologies than the prospect of truly disintermediating pharmacists from their manual, product-based environment and fulfilling the promise made to patients through the Oath of Maimonides.

\section{Reference}

1. Commission on the Future of Health Care in Canada. Building on values: the future of health care in Canada-final report. Saskatoon (SK): The Commission; 2002 [cited 2009 Feb 10]. Available from: http:// www.hc-sc.gc.ca/hcs-sss/alt_formats/hpb-dgps/pdf/hhr/romanow-eng.pdf

Richard Jones, RPh, BSc, BSP, is President and Internal Liaison for CSHP. 